\title{
TOMÁS MILANS (1672-1742), SU VIDA Y PRODUCCIÓN MUSICAL
}

\author{
César ALCALÁ
}

\section{Biografía}

Tomás Milans nació en la localidad barcelonesa de Canet de Mar en marzo del año 1672. En la partida de nacimiento podemos leer lo siguiente:

\begin{abstract}
Als set de mars de lo any mil sis cens setanta y dos, fou batejat en las fonts Baptismals de la parrochial iglesia de Canet de Mar, Tomás Francisco Benet Felix, fill legitim y natural del Sr. March Antoni Milans ciutadà honrat de Barcelona y Mariana muller de aquell.
\end{abstract}

Como ocurre con muchos compositores de aquella época, desconocemos el día exacto de su nacimiento, pero sabemos que era frecuente bautizar al niño el mismo día o al siguiente de su nacimiento. Así pues, Tomás Milans debió nacer entre el 7 y el 8 de marzo del 1672.

Tomás Milans estaba relacionado con el santo catalán San Josep Oriol. Supongo que San Josep Oriol debió marcar la vida de nuestro maestro. Sabemos que, durante su juventud en Barcelona, Tomás Milans se relacionó bastante con él y, a su vez, el santo subió muchas veces a Canet de Mar y a Arbucias —provincia de Gerona-, donde era otra parte de la familia Milans. Poco antes de morir, legó a Tomás Milans su manto corto de chamalote - su pieza de vestuario más lujosa-. Se cuenta que el Santo, poco antes de morir, le rogó a Tomás Milans, «para dar más calor a su afectuosa aspiración con la memoria de la tormentosa pasión de Cristo crucificado y de su dolorosa Madre», que le cantasen a voz baja la secuencia «Stabat Materd Dolorosa» cuatro infantillos del palau de la Comtessa a los que acompañó con arpa el propio maestro de capilla Tomás Milans'.

1. San Josep Oriol (Barcelona 1650 - Barcelona 23 de marzo del 1702). Perteneció a la Escolanía de la Iglesia de Santa María del Pino. En el año 1676 fue ordenado sacerdote en Vic. Ejerció en la Iglesia de San Felipe Neri de Barcelona y en la de Canet de Mar. En el 1806 lo beatificaron. En el 1909 fue canonizado. Fue muy popular en vida y, según la tradición, realizó muchos milagros. Su cuerpo inhumado en Santa María del Pino desapareció a consecuencia de la Guerra Civil (1936-39). El pueblo lo conocía por Mossén pa i aigua - Mossén pan y agua_- porque sólo se alimentaba de estos dos productos, de ahí su extremada delgadez. 
Dentro de la población barcelonesa de Canet de Mar, la familia de Milans era de las más nobles. Nada sabemos de la vida de Tomás Milans antes de entrar en la capilla del Palau de la Comtessa. Conocemos que tenía un hermano, Carlos que fue organista en Martorell y padre del maestro de capilla de la iglesia de los Santos Justo y Pastor de Barcelona, Tomás Milans y Campís. Sabemos, eso sí, que tomó los hábitos sacerdotales. Me es difícil precisar dónde, cómo y cuándo inició sus estudios sacerdotales pero, por lo que he podido investigar, Tomás Milans fue escolar de cota en la Capilla del Palau de la Comtessa, posiblemente bajo la dirección del maestroFelipe Olivellas. Así pues, sus estudios sacerdotales debió realizarlos en Barcelona y, con toda probabilidad, bajo la estrecha vigilancia de Sant Josep Oriol.

Milans debió ser ordenado sacerdote alrededor del 1700. Ese año debió entrar como maestro interino del Palau. De ese año, también, es la primera composición que conocemos de él. Se trata de un villancico dedicado al recientemente inaugurado Convento de Capuchinos de Martorell -hoy en día convertido en Biblioteca-. Aunque en un principio nos pueda parecer extraño que Martorell pidiera una obra a Tomás Milans el caso no es tan raro. Los Requesens —que eran los propietarios del Palau Reial Menor de Barcelona, donde estaba la capilla del Palau de la Comtessa-, eran marqueses de Martorell.

Un dato curioso nos lo ofrece el Archivo de la Seu de Manresa. En el «Libre d'Entrades de Quotidianes», con fecha del 1702 aparece la siguiente nota:

«Tomás Milans que era cantor de Palau y beneficiat de la Seu.»

El beneficio, con toda probabilidad era uno de los que tenían los Requesens en la Catedral de Barcelona. Como que Milans fue elegido maestro de capilla del Palau de la Comtessa el año 1702, esta nota, simplemente nos indica que, antes de ser elegido maestro del Palau pasó una temporada en Manresa. Desgraciadamente los archivos de Manresa no nos aportan ningún dato más de su presencia en esta población catalana. Anotemos que el archivo de la Seu de Manresa fue destruido en dos incendios: uno en el 1714 y en otro más recientemente, en el 1936. Apuntemos el nombre de los dos posibles maestros de capilla que se encontró Tomás Milans durante su estancia en Manresa: Francesc Espelt (maestro de capilla del 1700 al 1702) y Pere March (maestro de capilla del 1702 al 1713).

Tomás Milans fue maestro de capilla del Palau de la Comtessa hasta el 1714. Ese año marchó a Gerona. Desgraciadamente poco más sabemos de su paso por el Palau. Sólo nos quedan algunas partituras y algunos papeles sueltos que no aportan más datos a lo escrito hasta el momento. Como decía Milans marchó a Gerona pero, hagamos un poco de historia.

Ante la jubilación de José Gaz — maestro de capilla en Gerona del 1690 al 1711 -, se nombró a Gaspart Gibert como su sustituto, 7 de enero del 1712. Gibert duró poco en esta plaza pues murió el 17 de octubre del 1713. El 27 de noviembre de ese año fue elegido Salvador Campeny. Es curioso que este nuevo maestro de capilla desapareció al mes de ser elegido. El 6 de febrero del 1714 se confirmó en el cargo a Antonio Gaudí. El 27 de octubre de ese mismo año ya se nombra a Tomás Milans como maestro de capilla.

La primera vezque aparece el nombre de Milans en Gerona es el 31 de mayo del 1719, en el Libro de Pagos: 
Mestre T. Milans, paga per Terça $120 \mathrm{Ll}$; Mariano Sol, pbre. id $30 \mathrm{Ll}$.; Josep Briga, id. 30 Ll.; Rafael Gayolá, id 6 Ll. 3 s.; Antonio Lizoado, id 30 Ll.; Gabriel Camps, id. 10 Ll.; Manuel Jubert, religiós marcedari; id. $10 \mathrm{Ll}$.; Salvador Campeny, id. $30 \mathrm{Ll}$.; Miquel Brunet, id. $10 \mathrm{Ll}$.; Geroni Llisostella, id. $10 \mathrm{Ll}$.; Fleix Burrell, religiós carmelita, id. 5 Ll. y Pau Rosís, id. 12 Ll.

Resulta, pues, que estos eran los miembros de la capilla musical con la cual trabajó Milans al principio de estar en Gerona. Miquel Brunet y Manuel Jubert eran los organistas. El resto eran músicoscantores beneficiados. Prestemos atención a uno de los nombres: Salvador Campeny. Este fue el desaparecido maestro de capilla que ocupó el cargo del 27 de noviembre al 26 de diciembre del 1713. Así pues, la supuesta desaparición se debió más a una renuncia que a una huida quedando de nuevo reincorporado dentro de la capilla musical.

En los libros aparecen dos fechas en las cuales Tomás Milans estuvo enfermo. La primera de ellas data del 15 de marzo del 1715. En el acta dice que el médico lo visitó diez veces y que le hicieron una sangría - quizás para bajarle la fiebre—. La segunda referencia data del 16 de junio del 1717. En esta ocasión sólo nos dice que pagó la factura al médico por enfermedad.

A pesar de su talento musical, nunca puesto en duda, Milans no debió gozar de toda la consideración y el respeto que se le solía dedicar al maestro de capilla en cualquier catedral e iglesia. Esta afirmación la extraemos de la serie de datos que nos han llegado en los cuales nos hablan de las diferencias entre Milans y su capilla. Veamos:

- El 4 de mayo del 1716 el propio Milans observa cierta negligencia en algunos cantores.

- El 20 de marzo del 1726 observa la falta de cantores.

- El 17 de agosto del 1726 da queja que un miembro de la capilla le había reprochado la utilización de flautas dulces en vez de violines, en algunas obras.

- El 11 de mayo del 1728 se descubrieron irregularidades y abusos en la entrega de distribuciones a un escolar del coro. Se encarceló a dos miembros de la Catedral.

- El 19 de octubre del 1728 se puso en libertad a los dos encarcelados el 11 de mayo de ese mismo año.

- El 11 de enero del 1730 se produce un conflicto entre la capilla y Milans por diferencias de interpretación en los Estatutos de dicha capilla.

- El 24 de marzo del 1735 fueron reformados los estatutos.

A pesar de estos inconvenientes y malos entendidos entre la capilla y Milans hemos de anotar las nuevas incorporaciones y el aumento de efectivos instrumentales en la capilla:

- El 20 de noviembre del 1722 pidió la adquisición de una viola de arco.

- El 4 de noviembre del 1728 escribió la siguiente nota:

La capilla carece de trompeta y precisamente acaba de ofrecerse para ello un músico que convendría aconductar mediante salario remunerador y que sabe manejar varios instrumentos.

- El 17 de noviembre del 1731 da constancia que se debe retener en la capilla a José Anglada, al ser un excelente instrumentista de archilaüd y violín.

- El 24 de octubre del 1733 da constancia del pago de 20 libras anuales a un oboísta (abueso) y a un sacabuche. 
Los conflictos ente la capilla y Milans se acentuaron a medida que el maestro fue haciéndose más mayor.

El 21 de junio del 1732, cuando contaba con sesenta años, tomó como ayudante suyo a su sobrino -Tomás Milans y Campús- para «llevar lo compás». El Capítulo le pidió explicaciones sobre esta decisión. Milans les contestó que él era libre de tomar a quien quisiera para dirigir el compás. Esta contestación del maestro de capilla no debió sentar muy bien al Capítulo gerundense pues, al día siguiente se tomaron medidas ante la decisión de Milans. Reconocieron que Milans se había equivocado en la aplicación de los Estatutos establecidos en el año 1730. El Capítulo decidió mantener al sobrino de Milans hasta que se celebrara la próxima reunión y, en ella se empezó a pensar en la posibilidad de jubilar a Milans. La decisión de jubilación fue acompañada por una nota en la cual decían que sería conveniente pensar en ella porque, de lo contrario, la capilla y Milans nunca más estarían tranquilos. Todo aquel proceso creó una hostilidad entre ambas partes.

Los comisarios de Música Çanou, Roselló y de Sala contestaron que «por su parte ya habían hecho cuanto estaba a su alcance para aquietar los ánimos y que a partir de aquel momento Vuestra Señoria disponga lo más pertinente para el caso, ya que ellos, por su parte, renunciaban al cargo». El asunto perturbó la paz de la capilla. Tomás Milans se había ganado la fama de gran maestro y, esto, era una razón de peso ante la capilla musical. También era cierto que el maestro se hacía viejo y que, tarde o temprano, tendría que jubilarse, si no moría antes. Al cabildo gerundense se le planteaba una terrible papeleta. La suerte les acompañó.

El 4 de mayo del 1733 se convocaron unas oposiciones para un beneficio que había quedado vacante por la muerte del Rdo. Juan Cordoneda. Este beneficio era el de segunda arpa, con pericia de director. El cabildo convocó a Milans para que aceptara dicha plaza.

El 4 de agosto se celebraron las oposiciones. Quedó elegido el Rdo. Tomás Milans con el «placet» unánime de los 22 asistentes.

El 7 de agosto del mismo año tomó posesión de su escaño. Milans siguió luciendo las insignias doctorales.

El último evento público que realizó Milans se produjo el 20 de mayo del 1735 . Ese día presidió unas oposiciones. Fue elegido Masiano Codina, clérigo, como tenor, con el beneficio Lo Coc y Antonio Guardias, presbítero, como contralto, con el beneficio Manat.

El 25 de junio del 1735 solicitó la jubilación. Se le concedieron 50 libras anuales con la obligación de tañer el arpa segunda y llevar «lo compás» cuando ello fuera necesario por ausencia del maestro, participando de las ganancias de la capilla. Las condiciones que le impusieron a Milans no eran otras que las derivadas de su beneficio.

Después de su jubilación se realizaron unas nuevas oposiciones para elegir al nuevo maestro de capilla. A estas pruebas se presentaron:

Francisco Andreu de 37 años de edad, sacerdote y maestro de capilla de Urgell.

Tomás Milans y Campús, maestro de capilla de los Santos Justo y Pastor de Barcelona, sin ordenar todavía «in sacris» y cuyos conocimientos musicales están de manifiesto a través de su magisterio y por las composiciones suyas de repertorio en esta iglesia de Gerona. 
Enmanuel Gónima, sin ordenar todavía, de edad 23 años y según informes llegados de Barcelona, excelentemente dotado para dicho cargo.

Finalmente, fue elegido Enmanuel Gónima por 19 sufragios, mientras que los otros dos participantes obtuvieron dos cada uno. El nuevo maestro tomó posesión de su puesto como nuevo maestro de capilla de la Catedral de Gerona el 5 de octubre del 1735.

A propósito de lo dicho anteriormente y teniendo en cuenta los datos aportados antes sobre el año 1733, es momento de rectificar un error. Anglés-Pena, en su diccionario, incluyen el dato que Tomás Milans fue admitido como maestro de capilla de la Iglesia parroquial de los Santos Justo y Pastor de Barcelona el 1 de septiembre del 1733. Esta nota es errónea. Anglés-Pena se equivocan en dicha aformación. Tomás Milans nunca estuvo en esta capilla. El que sí estuvo, como hemos podido leer anteriormente, fue su sobrino Tomás Milans y Campús. Éste maestro había nacido en la localidad barcelonesa de Martorell el 7 de marzo del 1707. Durante los años 1719 al 1722 estuvo en Gerona como escolar del coro siendo educado musicalmente por su tío. Hasta su muerte —en el 1767— fue maestro de San Justo y Pastor de Barcelona.

La última reseña que tenemos de Tomás Milans aparece en el Libro de Obra del año 1735. Es lógico que la figura de Milans quede ensombrecida. El nuevo maestro de capilla eclipsa al viejo, el cual debe conformarse con tocar la segunda arpa y, muy de tanto en tanto marcar «lo compás». La citada reseña dice así:

Als 3 de desembre 1735 he pagat al Sr. Mestre de Capella Th. M. dues lliures onze sous per la cerilla per los cantors gastada fins dit día com consta de son compte... Memoria de la cera se ha consumit per servey de la Capella de la Sta. Igl. Cath. de Gerona en lo any 1735.

Per llum,

4 abril en las Lamentaciones $\quad 7$ sous

8 juny $\quad$ en las Maitines Corp. $\quad 7$ sous

14 agost en las Maitines Assumpta 7 sous

\section{Ll. 11 sous}

Item. Alsa 3 decembre 1735 he pagat al Sr. Mestre de Capella Th. M. cent y vint Lliureas per la terça caiguda lo ultim de setembre prop passat. Vers, Th. M. Despeses per la Capella de Música: Ed. Thomas Milans, 25 Ll., forma vere Gónima, $120 \mathrm{Ll} . »$

Después de esta cita no volvemos a encontrar el nombre de Tomás Milans hasta la fecha de su óbito. El viejo maestro murió la noche del 18 al 19 de enero del 1742 en Gerona. Como dice la partida de defunción:

qui praeterita nocte decessit, eligens sepulturam in villa de Canet de Mar a qua est oriendus.

Posiblemente la familia decidiera enterrarlo en su ciudad natal. Con tal motivo se hicieron los pasos pertinentes para llevar su cuerpo desde Gerona a Canet de Mar. Los funerales se realizaron los días 20 y 21 de enero del 1742. Los oficios funerarios tuvieron lugar en la Iglesia parroquialde San Pedro 
y San Pablo de Canet de Mar. Su cuerpo fue inhumado en dicha iglesia. Su cuerpo descansa en la tumba de la casa Milans.

\section{Producción musical}

Las obras de Tomás Milans se conservan en la Biblioteca de Catalunya, Archivo de Gerona y la Iglesia de Sant Pere de Canet de Mar.

\section{a) Obras de Tomás Milans conservadas en la Biblioteca de Cataluña}

En el Catàlech de la Biblioteca Musical de la Diputación de Barcelona, de Felipe Pedrell, encontramos la siguiente relación de obras compuestas por Milans y conservadas en la Biblioteca de Catalunya, antigua Biblioteca de la Diputación. Por lo que se ha podido comprobar en esta catalogación se mezclan las obras que compuso Tomás Milans, tanto en su estancia en el Palau de la Comtessa como en Gerona, con las compuestas por su sobrino, Tomás Milans i Campús, durante sus años como maestro de capilla de la iglesia de San Justo. Excluyendo una que lleva fecha, las otras es difícil diferenciar de quien son, aunque no nos cabe duda que la gran mayoría sean del Maestro de Gerona. El número que aparecerá antes de cada obra es el de catalogación que le dio Pedrell:

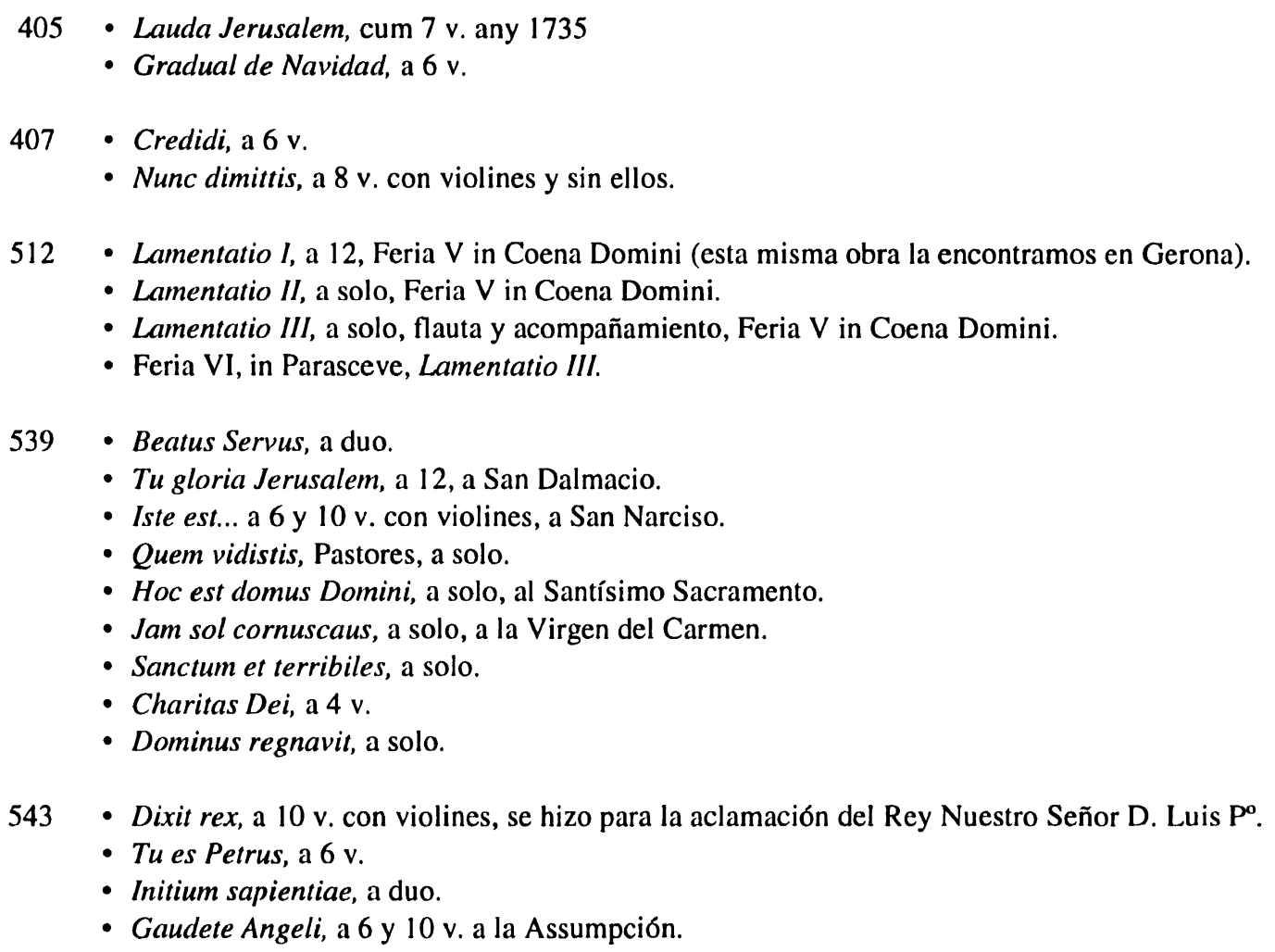


- Benedictus sit Deus Pater, a duo in festo a la Sanctissima Trinitatis.

- Gaudant in coeli, a duo.

- Virgo prudentissima, a 3 v. con violín.

567 - Laetatus sum, a 6 v. (año 1755) «esta composición es del sobrino, maestro de capilla de San Justo y Pastor, Tomás Milans i Campús».

- Letanía de la Virgen, a $4 \mathrm{v}$.

568 - Nunc dimittis, a $8 \mathrm{v}$.

- Reges Tharsis..., canon a 3 v., sine fine, a los Santos Reyes, 1734.

572 - Nunc dimittis, a $6 \mathrm{v}$.

618 - Magnificat, a $6 \mathrm{v}$.

- Magnificat, a $8 \mathrm{v}$.

- Magnificat, a $8 \mathrm{v}$.

675 - Alma Redemptoris, a 8 v. con violines.

676 - Salve Regina, a $6 \mathrm{v}$.

714 - Las flores, las aves, a 8 v. con ministriles, a la Assunción.

718 - Entre golfos undosos, a 12 y 16 v. al Santísimo Sacramento.

784 - En la muerte del justo, a 4 v. con violón, a la Pasión.

- Para divertir alegras, a duo, al Nacimiento.

- La gitana, que los montes, a 4. al Nacimiento.

- Ala, zagalas, ala, tono, a 4 v. al Nacimiento

- Si mi amor entre hilos, tono a solo, al Nacimiento.

786 - Lleve el compás mi manto, a solo.

- Una alma cariñosa, a 3 v. al Santísimo Sacramento.

803 - Ay que cayó, con violines, solo.

- Sicut erat in principio, solo.

824 - Sois de todo el orbe entero, a 4 v., a San Francisco de Paula.

852 - Suspende, infelice, a solo, al Santísimo Sacramento... «que se fan per una oposició de Tenor... Gerona en lo any 1731 ».

976 - Deja la aljaba y las flechas.

Dos son las piezas, sin música, que se han elegido de Milans conservadas en la Biblioteca de Catalunya y que no aparecen en el Catàlech de Pedrell. Se trata de dos villancicos:

Villancicos que se cantaron en la translación del Santísimo Sacramento de la Iglesia de los Padres Capuchinos de Martorell, puestos en música por Tomás Milans, 1700.

[7] 
Este primer villancico fue cantado por la capilla del Palau de la Comtessa de Palamós el 26 de septiembre del 1700. El manuscrito —cuyo tamaño es de $21,5 \mathrm{~cm}$-, está compuesto por cinco folios de letra y uno de portada. La letra que nos ha llegado es incompleta. Solamente conocemos dos villancicos completos, del tercero solamente tenemos los cuatro primeros versos. Igualmente desconocemos la música compuesta por Tomás Millans.

\footnotetext{
Villancicos que se cantaron en las solemnes fiestas que celebró el ejemplar y religiosísimo convento de Carmelitas Descalzas de la ciudad de Gerona por la canonización solemne de su extático y místico Doctor San Juan de la Cruz, siendo su maestro el licenciado Tomás Milans, 1727.
}

Este segundo villancico está dedicado a la memoria de San Juan de la Cruz con motivo de su canonización. El convento de esta orden de Carmelitas Descalzas de Gerona le pidió al maestro de capilla de la Catedral de Gerona - y, por consiguiente, al máximo representante musical de la ciudad—, la composición de una obra dedicada a la insigne figura del místico canonizado. Al ser compuestos estos villancicos por Tomás Milans, los cantos fueron realizados por los miembros de la capilla que él dirigía.

La obra fue un encargo, por consiguiente, no pasó a engrosar los fondos musicales de la Catedral de Gerona sino, desde un principio, a la orden carmelita. Que la obra fuera impresa en Barcelona no nos tiene que extrañar. El Convento de Carmelitas Descalzos — que en aquella época estaba en la calle Canuda de Barcelona-, poseía una importante imprenta situada en el actual Mercado de San José más conocido por el Mercado de la Boquería-. Esta imprenta carmelita no funcionó con regularidad. Se tienen noticias que funcionó a pleno rendimiento durante los siguientes tres períodos: 1724-28; $1762-$ 68; principios del siglo XIX, hasta la llegada francesa. A partir del $1746 \mathrm{y}$, hasta la invasión francesa existió una importante fábrica de fundición de letras, la cual trabajaba para España, Europa y América.

Desgraciadamente no se conservan los libros de cuentas - destruidos en las diferentes guerras que hemos sufrido durante los últimos dos siglos-, del período que nos ocupa, 1727. Por lo cual nos resulta imposible conocer cuánto dinero percibió Milans por la composición de estos villancicos.

El manuscrito - con un tamaño de $19 \mathrm{~cm}$-, está compuesto por 6 folios de letra y una portada. Desconocemos el nombre del letrista aunque, bien pudo ser uno de los padres carmelitas de Gerona. Leyendo la obra se ha descubierto una cierta semejanza entre la letra del villancico y unas coplas que incluyó Miguel de Cervantes en uno de sus relatos que componen las «Novelas Ejemplares», y que lleva por título: La Ilustre Fregona. Recordemos que Cevantes publicó la obra en el año 1613. Teniendo en cuenta la enorme popularidad que adquirió esta obra cervantina, no nos debe extrañar que esa influencia se viera reflejada en algunos versos de éste villancico.

La letra de este villancico nos ha llegado completa. Como ocurriera con el anterior villancico, desconocemos la música compuesta por Tomás Milans.

Veamos ahora las similitudes dichas anteriormente entre el poema de Miguel de Cervantes y el villancico de Milans: 
LETRA DEL VILLANCICO DE TOMÁS MILANS.

\author{
$\mathrm{Al}$ agua tributen \\ los tres elementos \\ aplausos festivos \\ con sus mudos ecos \\ pero lenguas se haga entre todos, \\ que no sea nuevo \\ El fuego, \\ $y$ da un esplendor \\ Ardores, \\ pues bien mirado \\ Ivan ya dio en sus ensayos \\ Rayo \\ que apenas lucieron, \\ Ya fueron, \\ no parando en estrellas, \\ centellas, \\ y sentidos los abismos, \\ en mal formadas querellas, \\ dicen que son favores \\ Ardores, Rayos, Centellas.
}

LETRA DE LA ILUSTRE FREGONA DE MIGUEL DE CERVANTES

¿Quién mejorará mi suerte?

La muerte.

Y el bien de amor, ¿quién lo alcanzará?

Mudanza.

Y sus males, ¿quién los cura?

Locura.

De este modo, no es cordura

querer curar la pasión,

cuando los remedios son

muerte, mudanza y locura.

¿Quién de amor venturas halla?

El que calla. 
¿Quién triunfa de su esperanza?

La Firmeza.

¿Quién da alcance a su alegría?

La Porfía.

Dese modo, bien podría

esperar dichosa palma

si en esta empresa mi alma

calla, está firme y porfía.

b) Obras de Tomás Milans conservadas en el Archivo de la Catedral de Gerona

En el Archivo Capitular de la catedral de Gerona se conservan siete obras de Tomás Milans:

1. Tono a solo al Santísimo Sacramento titulado: «Aparta, aparta», para voz y acompañamiento.

2. Recitado a solo titulado: «Detén, detén», para voz y acompañamiento.

3. Tono a 3 al Santísimo Sacramento titulado: «Porque alma tenga la idea», para tiple, alto y tenor con acompañamiento.

4. Salve Regina, escrita para dos coros formados por:

-Coro I: alto I y II.

-Coro II: tiple, tenor, bajo

con órgano y acompañamiento cifrados.

5. Solo al Santísimo Sacramento titulado: «Quién aunque hablando hiere». Solamente se conserva el acompañamiento cifrado.

6. Misa «Ecce sanctus magnus» a 8 voces. Solamente se conserva el bajo del segundo coro.

7. Lamentatio I, Feria V. Tiene una extensión de 32 páginas. La obra está estructurasda así:

-Coro I: tiples I y II, alto, tenor.

-Coro II: tiple, alto, tenor, bajo.

-Orquesta: violín I, II; flauta I, II; violón y acompañamiento

c) Obras de Tomás Milans conservadas en el Museo-Archivo de la Iglesia parroquial de San Pedro y San Pablo de Canet de Mar

La relación de obras conservadas en dicho archivo es la siguiente:

- «Si esto pasa y en su casa», solo con violines.

- «Esta lengua mia», solo.

- «Venid, venid zagales», a 4 voces. 
- Deseo pues buscar, a 4 voces.

- Imitando el serafin, solo.

- Salve Regina, a 6 voces.

- Una solera flora, solo.

- Hora Tertia para el día de Pentecostés, a 6 voces.

- Secuencia a 5 voces.

- Villancicos para la fiesta del Espíritu Santo, con violines.

- Magnificat a 8 voces.

- Magnificat a 6 voces (incompleto).

- Bate las alas, solo con violines.

- De aquel sacramento a 4 voces, con violines.

- Amantes a aprender a 4 voces, con violines.

- Celeste exaltación a 4 y 8 voces con violines.

- Cazador prodigioso a 4 voces con violín.

- En la más purgue, solo con violines.

- Todo es todo el pan a 4 voces.

- O mi Dios, a 4 voces.

- Suspende infelice, solo.

- Aparta, aparta, solo.

- Tu es Petrus, a 6 voces.

- Tu es Petrus a solo.

- Graduales Viderunt a 6 voces con violines.

- Hodie Rex Caelorum a 6 voces con violines.

- Al Sol que dos claris.

\section{Catálogo general de las obras de Tomás Milans}

\section{MUSICAL VOCAL RELIGIOSA}

-Solos, Tonos, Recitados.

\begin{tabular}{|c|c|c|c|}
\hline No. Am. & Tonal. & Cons. & Título e instrumentación \\
\hline 1 & & Canet & Si esto pasa y en su casa, con violines \\
\hline 2 & & Canet & Esta lengua mia \\
\hline 3 & & Canet & Imitando els serafin \\
\hline 4 & & Canet & Una solera flora \\
\hline 5 & & Canet & Es la más purgue, con violines \\
\hline 6 & & Canet & Bate las alas, con violines \\
\hline 7 & & Canet & Suspende infelice \\
\hline 8 & & Canet & Aparta, aparta. (Hay una copia en Gerona) \\
\hline 9 & & Canet & Tu es Petrus \\
\hline 10 & & Canet & Al Sol que dos claris \\
\hline 11 & & $\mathrm{BCN}(539)$ & Quem vidistis, pastores \\
\hline 12 & & $\mathrm{BCN}(539)$ & Hoc est domus, Domini, al Santíssimo Sacramento \\
\hline 13 & & $\mathrm{BCN}(539)$ & Jam sol cornuscaus, a la virgen del Carmen \\
\hline 14 & & $\mathrm{BCN}(539)$ & Sanctum et terribiles \\
\hline 15 & & BCN (539) & Dominus regnavit \\
\hline 16 & & $\mathrm{BCN}(786)$ & Lleve el compás mi manto \\
\hline
\end{tabular}




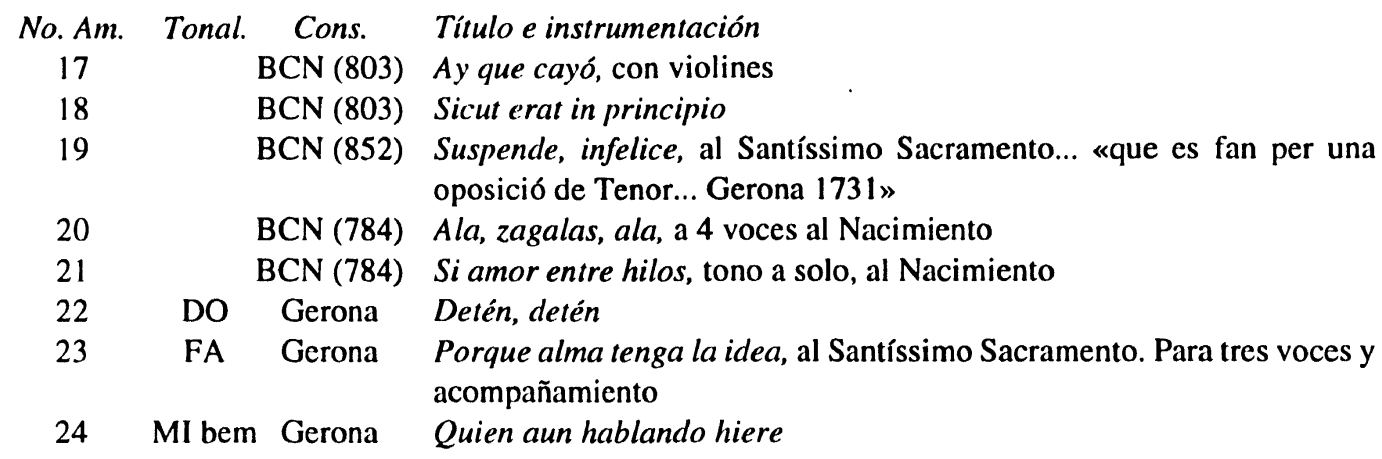

- Villancicos, Romances, Cantatas

\begin{tabular}{|c|c|c|}
\hline No. Am. & Tonal. & Título e instrumentación \\
\hline 25 & Canet & Venid, venid zagales, a 4 voces \\
\hline 26 & Canet & Deseo pues buscar, a 4 voces \\
\hline 27 & Canet & Hora tertia para el día de Pentecostés, a 6 voces \\
\hline 28 & Canet & Villancicos para la fiesta del Espíritu Santo, con violines \\
\hline 29 & Canet & De aquel Sacramento, a 4 voces \\
\hline 30 & Canet & Amantes a aprender, a 4 voces con violines \\
\hline 31 & Canet & Celeste exaltación, a 4 y 8 voces con violín \\
\hline 32 & Canet & Cazador prodigioso a 4 voces con violín \\
\hline 33 & Canet & Todo es todo el pan, a 4 voces \\
\hline 34 & Canet & O mi Dios, a 4 voces \\
\hline 35 & Canet & Tu es Petrus, a 6 voces \\
\hline 36 & $\mathrm{BCN}(714)$ & Las flores, las aves, a 8 voces con ministrales a la Asunción \\
\hline 37 & $\mathrm{BCN}(718)$ & Entre golfos undosos, a 12 y 16 voces al Santíssimo Sacramento \\
\hline 38 & BCN (784) & En la muerte del justo, a 4 voces con violón, a la Pasión \\
\hline 39 & $\mathrm{BCN}(784)$ & Para divertir alegres, duo al Nacimiento \\
\hline 40 & $\mathrm{BCN}(784)$ & La gitana, que los montes, a 4 voces, al Nacimiento \\
\hline 41 & $\mathrm{BCN}(786)$ & Una alma cariñosa, a 3 voces, al Santíssimo Sacramento \\
\hline 42 & $\mathrm{BCN}(824)$ & Sois de todo el orbe entero, a 4 voces, a San Francisco de Paula \\
\hline 43 & BCN (976) & Deja lo aljaba y las flechas \\
\hline 44 & $\mathrm{BCN}$ & $\begin{array}{l}\text { Villancicos que se cantaron a la translación del Santíssimo Sacramento } \\
\text { de la Iglesia de los Padres Capuchinos de Martorell, año 1700. (Incom- } \\
\text { pleta) }\end{array}$ \\
\hline 45 & $\mathrm{BCN}$ & $\begin{array}{l}\text { Villancicos que se cantaron en las solemnes fiestas que celebró el } \\
\text { ejemplar y religiosísimo convento de Carmelitas Descalzas de la ciudad } \\
\text { de Gerona por la canonización solemne de su extático y místico doctor } \\
\text { San Juan de la Cruz. Año } 1727 \text {. (Incompleta) }\end{array}$ \\
\hline
\end{tabular}

- Magnificat, Salmos, Secuencias, Responsorios

\begin{tabular}{|c|c|c|c|}
\hline No. Am. & Tonal. & Cons. & Título e instrumentación \\
\hline 46 & & Canet & Magnificat a 8 voces (Hay una versión en Barcelona [BCN 618]) \\
\hline 47 & & Canet & $\begin{array}{l}\text { Magnificat a } 6 \text { voces (Hay una versión en Barcelona [BCN 618]) } \\
\text { (Incompleta) }\end{array}$ \\
\hline 48 & & Canet & Secuencia a 5 voces \\
\hline 49 & & $\mathrm{BCN}(618)$ & Magnificat a 8 voces \\
\hline
\end{tabular}


- Himnos, Antífonas, Graduales

\begin{tabular}{|c|c|c|c|}
\hline No. Am. & Tonal. & Cons. & Título e instrumentación \\
\hline 50 & & Canet & Salve Regina a 7 voces \\
\hline 51 & & Canet & Graduales Viderunt a 6 voces con violines \\
\hline 52 & & Canet & Hodie Rex Caelorum a 6 voces con violines \\
\hline 53 & & $\mathrm{BCN}(405)$ & Gradual de Navidad, a 6 voces \\
\hline 54 & & BCN (407) & Credidi a 6 voces \\
\hline 55 & & $\mathrm{BCN}(407)$ & Nunc dimittis, a 8 voces, con violines y sin ellos \\
\hline 56 & & $\mathrm{BCN}(539)$ & Beatus Servus, a duo \\
\hline 57 & & $\mathrm{BCN}(539)$ & Tu gloria Jerusalem, a 12 voces, a San Dalmacio \\
\hline 58 & & $\mathrm{BCN}(539)$ & Iste est... a 6 y 10 voces con violines a San Narciso \\
\hline 59 & & BCN (539) & Charitas Dei, a 4 voces (Hay una versión en Canet de Mar) \\
\hline 60 & & $\mathrm{BCN}(543)$ & $\begin{array}{l}\text { Dicit rex, a } 10 \text { voces, con violines, se hizo para la aclamación del Rey } \\
\text { Nuestro Señor D. Luis I }\end{array}$ \\
\hline 61 & & $\mathrm{BCN}(543)$ & Initium sapientiae, a duo \\
\hline 62 & & $\mathrm{BCN}(543)$ & Gaudeate Angeli, a 6 y 10 voces a la Asunción \\
\hline 63 & & $\mathrm{BCN}(543)$ & Gaudant in coeli, a duo \\
\hline 64 & & $\mathrm{BCN}(548)$ & Virgo prudentissima, a 3 voces con violin \\
\hline 65 & & $\mathrm{BCN}(568)$ & Nunc dimittis a 8 voces \\
\hline 66 & & $\mathrm{BCN}(675)$ & Alma Redemptoris, a 8 voces, con violines \\
\hline 67 & DO & $\mathrm{BCN}(676)$ & $\begin{array}{l}\text { Salve Regina a } 6 \text { voces (Conservamos otras dos versiones en Canet de } \\
\text { Mar y Gerona) }\end{array}$ \\
\hline 68 & & $\mathrm{BCN}(572)$ & Nunc dimittis a 6 voces \\
\hline 69 & & Gerona & Salve Regina a 5 voces \\
\hline
\end{tabular}

\section{- Lamentaciones}

No. Am. Tonal. Cons. Título e instrumentación

70 MI bemBCN (512) Lamentatio I, a 12 voces Feria 5 in Coena Domini (Hay una copia en Gerona)

71 BCN (512) Lamentatio II, a solo, Feria 5 in Coena Domini

72 BCN (512) Lamentatio III, a solo, flauta y acompañamiento. Feria 5 in Coena Domini

73 BCN (512) Lamentatio III, in Parasceve, Feria 6

- Misas y partes de la Misa

$\begin{array}{cccl}\text { No. Am. } & \text { Tonal. } & \text { Cons. } & \text { Título e instrumentación } \\ 74 & \text { DO } & \text { Gerona } & \text { Misa «Ecce sanctus magnus» a } 8 \text { voces. (Incompleta) }\end{array}$

\section{Anexos}

Se ha creído conveniente, con el fin de ampliar el estudio musicológico realizado sobre Tomás Milans, incluir en éste Anexo el nombre de los otros Milans que conocemos. 
Milans

Desconocemos la vida de este compositor catalán que, con toda probabilidad tuviera relación con la familia de Tomás Milans, al ser el apellido Milans oriundo de Arbucias. La familia Milans tuvo tierras en Arbucias y Canet de Mar.

Sabemos que vivió sobre el siglo XV. Desconocemos a cual de estas dos capillas musicales perteneció: a la del rey católico Fernando II (1452-1512) o a la de su padre Juan II (1458-1479). Los manuscritos de esta época no nos dan ninguna referencia sobre este Milans.

Dos son las obras conservadas:

- $O$ rex noster et Deus (conservada en el Orfeó Català, manuscrito 5 folio 65).

- «O bone Jesu, illumina oculos meos», para cuatro voces (conservada en el Orfeó Català, manuscrito 5 folio 69).

\section{Carles Milans}

Organista y compositor catalán, nacido en Canet de Mar. Fue organista en la parroquia de Santa María de Canet de Mar (1695-1724). Su hijo fue maestro de capilla en San Justo y Pastor de Barcelona.

\section{Tomás Milans y Campús}

Tomás Milans y Campús, nacido en Martorell el 7 de marzo del 1707. Su padre Carlos Milans era organista en Martorell. En el período comprendido entre los años 1719 al 1722 fue escolar de coro en Gerona, donde su tío Tomás Milans era el maestro de capilla.

El 21 de junio del 1732 tomó a su sobrino como ayudante para «llevar lo compás». Tomás Milans Campús permaneció como ayudante de su tío hasta mediados del año siguiente, 1733.

En septiembre del 1733 podemos leer lo siguiente en las Actas de la Iglesia Parroquial de los Santos Justo y Pastor:

Admisió de Tomás Milans clergue lo primer de mes de setembre més provinem fos admis a les comunes y oridianes... due venir lo mestre de capella.

A mediados del 1735 debió pedir permiso para ir a Gerona para tomar parte de las oposiciones que se hicieron con motivo de la jubilación de su tío. En las Actas capitulares de Gerona podemos leer la siguiente acta con referencia a las oposiciones:

... el Rdo. Francisco Andreu, de 37 años de edad, sacerdote y maestro de capilla de Urgel, cuya pericia, se
dice, solamente se conjetura por el cargo que ostenta; Tomás Milans, maestro de San Justo y Pastor de
Barcelona, sin ordenar todavía «in sacris» y cuyos conocimientos musicales están de manifiesto a través de
su magisterio y por las composiciones suyas de repertorio en esta iglesia de Gerona. Y, por último, Enmanuel
Gonima, sin ordenar todavía, de edad 23 años y según informes llegados de Barcelona excelentemente
dotado para dicho cargo. Verificada como de costumbre la votación, Gonima obtuvo 19 sufragios, Francisco 
Andreu 2 y otros 2 Thomas Milans, en total 23 papeletas. Así pues, por aplastante mayoria de votos quedó elegido nuevo maestro de capilla de la Catedral de Gerona Enmanuel Gonima.

Tomás Milans i Campús debió regresar a Barcelona después de las oposiciones aunque el registro de San Justo y Pastor no da referencia a esa vuelta. En las Actas con fecha del 26 de agosto del 1737 podemos leer una nota firmada por los «obrers» de San Justo y Pastor en la cual piden al Cabildo que perpetúe a Tomás Milans como maestro de capilla.

Los «obrers» que firmaban aquella carta eran: Rdo. Tomás Esteve, don Joseph Rodés, Bernat Canes, Joseph Calvet, Joseph Blanch, Dr. Olaguer Torras, Dr. Pere Corsino, Carlos la Peña, Ramón Cunill, Dr. Bonaventura Avench, Jauma Pau, Bonaventura Clavá, Felip Palet, Dr. Juan Sevilla, Pere Baña, Joseph Cusana y Francisco Javier Simó. Todos ellos eran presbíteros y beneficiados de dicha Iglesia. El manuscrito dice lo siguiente:

\begin{abstract}
... de Thomás Milans clergue mestre de capella de la Parroquial Iglesia dels era estat suplicat de volverlo a perpetuar en dit ofici de mestre de capella a di de poderse promoure al ordres sagrats judicant esser eixo lo millor medi per poderho lograr i a la qual petició havían assentit dits Señors obrers, per veurerlo desconsolat. Respecte a la Repulsa del magisteri de la Cathedral, comprenent no esser fora de vaho, temblant petició, puix no aventien desumaresca eixa gracia dit Tomás Milans y que sempre havia cumplert a sas obligacions: Paro, que com aixo es in acte que dits Señors obrers sol no poden ferho, sino que la Rat. Comunitat. den consentirhi també i firmanlo juntament, suplicavan de voler atendre a dita Perició...

... se passá a votar sobre dita Proposició y apres y differents Vahon si fonds resolt per dita Rat. Comunitat per pluralitat de vots, de que se consedi a dit Thomás Milans, la Perpetuació en dit magisteri donant gust en aixó a dits Señors obrers...

... Perpetuaven al dit Thomás Milans en lo ofici de $\mathrm{m}^{\circ}$ de capella de dita parroquial Iglesia donant, concedint y admetent perpetualment dits Rat. vicari perpetuo y Comunitat y los dits Señors obrers Vesp. a dit Tomás Milans en dit noms de $\mathrm{m}^{\circ}$ de capella a totes las disbulucions, luenos y emolumento que a semblants membres de la capella de dita Esglesia los Predecesors, dita Rat. Comunitat y dit Señors obrers han acostumat donar, concedir y admalzer, y lo dit Tomás Milans clergue a ditas cosas present a aceptar la dita Perpetuació de $\mathrm{m}^{\circ}$ de capella al Referiment de moltes gracias y Besament de mans, ne fu: com aixi uns llargament es de veurer del Acte de dita Perpetuacio rebut en poder de Sever Pujol notari public de Barcelona...
\end{abstract}

Toda la resolución quedó perpetuada en el Acta que fue firmada por el notario público de Barcelona, el señor Severo Pujol.

El nombre de Milans i Campús vuelve a aparecer en marzo del 1741 cuando se dice que fue ingresado en la enfermería. El cabildo hace notar que el maestro de capilla deberá abonar la cuenta en las mismas condiciones que los beneficiarios y la Reverenda Comunidad. Con lo cual se hace notar que el médico pretendía cobrar más a Milans que al resto de los integrantes de la Iglesia de los Santos Justo y Pastor y que, por eso, el Cabildo decidió salir en su favor y comunicarle al médico que tanto privilegio tenía el maestro de capilla —en el trato, se sobreentiende—, como los demás miembros de la Iglesia.

El 7 de octubre del 1747 se hace una consulta por la cual se preguntaba si el maestro y el organista se podían «gaudissen de la presencia de quince días», es decir, si podían estar fuera de la iglesia durante este período de tiempo. El Acta no nos especifica el motivo de este alejamiento. El Cabildo no les concedió dicha exclusión momentánea. Recordaremos que el organista de Sants Just i Pastor durante ese período fue Francisco Vilar. 
Tomás Milans i Campús debió morir en Barcelona el año 1767, pues ese mismo año se hacen oposiciones para elegir un nuevo maestro de capilla. El sustituto de Milans - con carácter perpetuo-, fue Joan Nogués que permaneció en el cargo hasta el 1815.

Se conservan pocas obras de Tomás Milans y Campús. En la Biblioteca de Cataluña hay estas tres que, curiosamente han sido atribuidas a su tío. En el archivo de la Iglesia de San Justo y Pastor no se conserva ninguna obra de él. Así pues, estas son las únicas tres obras que conservamos de Tomás Milans y Campús:

1. Laetatus sum, a 6 voces, año 1755.

2. Letania a la Virgen, a 4 voces.

3. Lauda Jerusalem, a 7 voces, año 1735.

\section{Bibliografía}

1. La Capilla de música de la Catedral de Gerona (Siglo XVIII) por Francisco Civil Castellví. Anales del Instituto de Estudios Gerundenses (1968-69).

2. Deliberaciones del Cabildo Gerundense recogidas en las Resoluciones Capitulares.

3. Libro de Pagos de la Catedral de Gerona.

4. Llibre de Noms i Cognoms dels Escolans de la Capella de Música y Cor de la Santa Esglesia de Girona.

5. Libro de la Obra de la Catedral de Gerona.

6. Archivo del Palau de la Comtessa de Sant Cugat del Vallès (Barcelona).

7. Archivo de la Iglesia parroquial de los Santos Justo y Pastor (Barcelona). 